\title{
Avaliação, agências e especialistas: padrões oficiais de qualidade da educação superior*
}

José Carlos Rothen **

Gladys Beatriz Barreyro ***

\section{Resumo}

0 texto discute a questão do estado avaliador/ regulador no Brasil após a LDB/ 1996, focalizando as agências e instituições que julgam e definem os padrões de qualidade da educação superior (graduação). No início do governo $\mathrm{FHC}$, a definição destes padrões ocorria no âmbito do MEC, pelas Comissões de Especialistas e, depois, pelo INEP. No governo Lula, foram criadas instâncias com o papel de coordenar a avaliação, sendo a definição dos critérios de qualidade, de competência das Secretarias do MEC e da CONAES. Assim, durante todo o processo pós-LDB, a definição da qualidade foi realizada por acadêmicos, reunidos em diversas comissões, que se foram formalizando e institucionalizando, visando à legitimação da avaliação pela profissionalização.

Palavras-chave: Educação superior. Avaliação e regulação da educação superior. Padrões de qualidade.

\section{Evaluation, agencies and experts: official standards of quality of higher education Abstract}

This paper analyses the evaluative/regulating State in Brazil after the $L D B / 1996$, focusing on the regulating agencies and institutions that define the quality standards in higher education. At the beginning of Fernando Henrique Cardoso's Administration, this role was first played by commissions integrated by experts

\footnotetext{
"Este é uma versão revista e ampliada do trabalho apresentado no XXIII Simpósio Brasileiro de Política e Administração da Educação, promovido pela ANPAE e realizado na UFRGS de 11 a 14 de novembro de 2007. 0 texto é resultado do projeto de pesquisa "Avaliação das Instituições Brasileiras de Educação Superior: politica, história, concepções, atores e marcos legislativos", que contou com apoio da FAPEMIG para o subprojeto "Avaliação e Regulação da Educação Superior brasileira: história e políticas" e da FAPESP para subprojeto "Avaliação e Regulação da Educação Superior: concepções e atores".

“- Doutor em Educação; Professor do mestrado em Educação Superior, Centro Universitário do Triângulo (UNITRI) Uberlândia, MG; e membro do Grupo de Estudos e Pesquisa em Política e História da Avaliação da Educação Superior (GEPPHAES). E-mail: josecarlos@rothen.pro.br

-.”- Doutora em Educação; Professora na Universidade de São Paulo (USP), Escola de Artes, Ciências e Humanidades e do Programa de Pós-Graduação em Integração da América Latina (Prolam); Membro do GEPPHAES. E-mail: gladysb@usp.br
} 
from the Ministry of Education and, then, by INEP. During Lula's administration, instances were created to coordinate the evaluation, however, MEC and CONAES were responsible for defining the quality criteria. Therefore, during the period post-LDB ad-hoc commissions of experts and academics were created, attempting to legitimate the evaluation through the professionalization Keywords: Higher education. Higher education evaluation and regulation. Quality standards.

\section{Evaluación-agencias $y$ especialistas: padrones de calidad de la educación superior. Resumen}

El texto discute la cuestión del estado evaluador/regulador en Brasil, en el periodo posterior a la Ley de Directrices y Bases de la Educación Nacional de 1996, focalizando en las agencias e instituciones que juzgan y definen los padrones de calidad de la educación. En el gobierno de Fernando Henrique Cardoso, al principio, la definición ocurría en el ámbito del Ministerio de la Educación, realizada por Comisiones de Especialistas y después, por el Instituto de Estudios e Investigaciones Educativas (INEP). En el gobierno de Lula da Silva, fueron creadas instancias con el rol de coordinar la evaluación y fue establecida la competencia de las Secretarias del Ministerio de Educación y de la CONAES (Comisión Nacional de Evaluación de la Educación Superior), para la definición de los criterios de calidad. Así, durante todo el proceso posterior a la aprobación de la $L D B$, la definición de la calidad fue realizada por los académicos, reunidos en diversas comisiones que fueron formalizándose e institucionalizándose progresivamente con el objetivo de conseguir la legitimación de la evaluación por la vía de la profesionalización. Palabras clave: Educación superior. Evaluación y regulación de la educación superior. Padrones de calidad

\section{A definição dos padrões de qualidade na avaliação da educação superior: agências e comissões de especialistas}

Claudio Rama (2006) postula a existência de três reformas universitárias na América Latina. A primeira delas, produto de Córdoba, 1918, tinha como princípios fundamentais a autonomia universitária e o governo colegiado. A segunda, a ampliação do acesso pela via privada, e a terceira, em curso, a autonomia avaliada no contexto da internacionacionalização da educação. Na maior parte dos países, a segunda reforma aconteceu desde a década de 50 até finais da década de 80 , e a terceira reforma, desde a década de 90 e continua.

${ }^{1}$ Em palavras de Krotsch (2003). 
As considerações de Rama, sobre a segunda reforma da educação superior, podem ser aplicadas para descrever o cenário brasileiro, considerando que, no Brasil, a expansão iniciada no final da década de 60 teve outro pico em meados da década de 90. A segunda reforma teve por características a conformação de um modelo de caráter dual que contava com:

[...] una educación pública con restricciones de acceso, basada en limitaciones del financiamiento público y en exámenes de conocimientos adquiridos en el ciclo educativo previo y un sector privado con restricciones en función de los ingresos de los hogares y de la desigual distribución de la renta (RAMA, 2006:32).

A nova realidade é caracterizada pela diversificação das universidades públicas (estadualização e municipalização, especialização, regionalização e divisão de unidades existentes) e o desenvolvimento de um setor privado, para dar resposta à demanda por maior acesso à educação superior. Na década de 90, essa ampliação, no Brasil, aconteceu, mormente, pela intensificação da criação de instituições não universitárias e pela desregulação, guiada pelo discurso do "mercado livre".

Segundo Rama (2006, p. 68), "[...] la ausencia de estándares básicos y de estructuras públicas de control permitió que se ofertaran opciones educacionales de muy baja calidad" o que, muitas vezes, gerou práticas de corrupção e excessiva mercantilização. Ele afirma que é na terceira reforma da educação superior, já com o viés da internaciolização, que as políticas públicas e o Estado assumem a função de regulador: fiscalizar, supervisionar e controlar.

Com instituições orientadas para o mercado e a sua respectiva massificação, houve uma queda na qualidade da educação, o que levou ao estabelecimento de sistemas de garantia de qualidade, "[...] a través de la creación de ministerios y viceministerios y del establecimiento de sistemas nacionales de aseguramiento de la calidad más rígidos, abarcadores, especializados y autónomos" (RAMA, 2006, p. 154), assumindo o Estado papel avaliador ou regulador. Assim, esse poder de regulação derivou na criação de agências com a finalidade de garantir a qualidade. Essas agências - uma nova instituição na realidade latino-americana - exercem a função de "polícia educativa"2, pois definem níveis mínimos de qualidade, critérios de autorização e funcionamento das instituições e outras regulações à liberdade de concorrência.

Apesar de ser um dos conceitos mais relevantes ao se tratar da avaliação da educação superior, não existe um consenso para a definição do que seja a quali-

\footnotetext{
${ }^{2} 0$ Poder de Polícia é uma das dimensões do Poder Executivo, Di Pietro (2006,) o define como a atividade prevista em lei pela qual a liberdade do individuo é restringida visando o bem comum.
} 
dade. Segundo Ginken e Dias (2007), em algumas definições, a qualidade é apresentada como a conformidade com um standard, um patamar, o que leva à definição prévia de quais seriam os resultados ou objetivos desejados. Assim colocada a questão, trata-se de saber quais são esses standards, em que se baseiam, quem os define, de onde procedem. Dessa forma, mais que defini-la, procede-se a descrever seus componentes ou elementos fundamentais, o que leva ao estabelecimento de standards, critérios, metodologias, etc. que permitam realizar sua aferição (FERNANDEZ LAMARRA, 2007).

Uma outra vertente leva a considerar a qualidade em relação com o contexto político, econômico e sociocultural, sendo entendida como eficiência nos processos, eficácia nos resultados e relevância, considerada essa última como o impacto e valor das suas contribuições, no que diz respeito às necessidades e problemas da sociedade. (FERNANDEZ LAMARRA: 2007, p. 41).

Nessa mesma linha, para Dias Sobrinho (2000, p. 212) a qualidade da educação é considerada como: "[...] um juizo valorativo que se constrói socialmente. É um atributo ou um conjunto de propriedades que definem uma coisa e a distinguem das demais, de acordo com julgamentos de valor praticados num determinado meio".

Esses juizos de valor não são produzidos aleatoriamente, pois requerem um mínimo de elementos comparativos, ou seja, a qualidade de uma instituição é considerada em relação com a de outras instituições. Além disso, o autor considera que:

Os juizos de valor da comunidade científica devem ser confrontados com a apreciação crítica da comunidade externa. Avaliar a qualidade implica necessariamente uma tomada de posição que pressupõe uma escolha de um sistema valorativo, dentre vários outros possíveis, num determinado meio social (DIAS SOBRINHO, 2000, p. 212).

Fernandez Lamarra esclarece que a qualidade também depende de quem a está definindo:

[...] para los académicos se refiere a los saberes, para los empleadores a competencia, para los estudiantes a la empleabilidad, para la sociedad a ciudadanos respetables y competentes y para el Estado, según la concepción que asuma, puede variar de aspectos vinculados con el desarrollo social y humano, a la eficiencia, a los costos y a los requerimientos de capital humano. (FERNÁNDEZ LAMARRA, 2007, p. 41). 
Neste estudo, consideramos a qualidade como definida socialmente.

Devido às consequências regulatórias, a definição dos padrões de qualidade que se tornam referência para os processos de avaliação influencia diretamente o modelo de educação superior que se adota: assim ao explicitar quais as agências e os atores que determinam esses padrões, visa-se contribuir na discussão de sua legitimidade ${ }^{3}$.

No Brasil, na década de 90, a avaliação da educação superior (graduação) constituiu-se num dos eixos das políticas para a educação superior. Na primeira metade da década, desenvolveu-se o Programa de Avaliação da Universidade Brasileira (PAIUB). Apesar de gerido pelo Estado, originou-se no seio das universidades e tinha como características a definição dos padrões de qualidade, a elaboração da proposta, bem como a sua execução pelas Instituições. A partir de 1995, com a exponencial expansão do setor privado, no contexto de Reforma do Estado e da intensificação das privatizações no Governo Fernando Henrique Cardoso ${ }^{4}$, a avaliação tornouse o eixo central da política educacional e passou a ser realizada pelo Estado.

No novo desenho institucional proposto, buscava-se diminuir ao máximo a intervenção regulatória direta do Estado com a criação de agências independentes para regular os diversos serviços que, tradicionalmente, eram fornecidos pelo Estado - por exemplo, telecomunicações, energia, etc.

Nesse contexto, objetiva-se mostrar as particularidades do processo brasileiro no que diz respeito às formas que adquire o estado avaliador/regulador, mostrando quem julga e define os padrões de qualidade do sistema (agências, instituições e atores), sobretudo no período posterior à Lei de Diretrizes e Bases da Educação Nacional (LDB) (BRASIL, 1996), até o final do primeiro governo Lula.

A metodologia usada consistiu na análise dos atos normativos que fixaram os responsáveis pela definição dos padrões de qualidade utilizados na avaliação da educação superior.

\section{O Governo Fernando Henrique Cardoso (FHC)}

A discussão de quem determina os padrões de qualidade da educação utilizados como referência na avaliação de Instituições e Cursos não tem recebido e não recebe a devida atenção. Normalmente, a discussão relaciona-se aos objetivos gerais da avaliação e aos seus usos. Alguns atores consideram que seria o Conselho Nacional de Educação (CNE) a instância que a definiria. Representa essa expectativa

\footnotetext{
${ }^{3}$ Uma análise sobre os indicadores de qualidade, utilizados na avaliação da educação superior brasileira, pode ser consultado em Dias, Horiguela e Marchelli (2006).

${ }^{4}$ A política administrativa/econômica desse periodo tinha como norte que o Estado deveria deixar de ser provedor de serviços relacionados com a infra-estrutura e passá-los para a iniciativa privada.
} 
a posição de Edson Nunes (2002) - acadêmico, conselheiro do CNE, e ex-presidente do órgão -, que defendia o funcionamento desse Conselho como agência reguladora, de caráter técnico, estabelecida pelo poder legislativo, que seria um mini-Estado dentro do Estado. Era essa a expectativa dos que consideravam a educação superior como um mercado, no qual iriam encaixar-se as agências reguladoras. As agências:

[...] não deviam ser representativas. Ao contrário deveriam ser técnicas, em função mesmo da área-fim sobre a qual teriam mandato regulatório. A 'teoria" que informa, contemporaneamente, a criação dos comitês independentes nos Estados modernos, é a de que os temas sob escrutínio, por sua natureza especializada, mereceriam atenção técnica incompatível com a estrutura representativa regular do Estado moderno (NUNES, 2002, p. 37).

Contudo, não foi o que ocorreu, o CNE, instituído para substituir o extinto Conselho Federal de Educação ${ }^{5}$, perdeu parte das funções de regulação para o Ministério da Educação Secretaria de Educação Superior (SESu) e Instituto Nacional de Estudos e Pesquisas Educacionais (INEP). Isto apesar de o Conselho ter sido incumbido de funções normativas, deliberativas e de assessoramento ao MEC. (BARREYRO; ROTHEN, 2007, p. 137-138).

Com vistas à Educação Superior, o CNE "[...] foi planejado para trabalhar predominantemente na garantia das funções avaliativas do Estado" (GOMES, 2002, p. 279), exercendo a atividade de deliberação sobre as seguintes questões: as diretrizes curriculares, os estatutos das universidades, os relatórios para reconhecimento periódico de cursos de mestrado e doutorado, o credenciamento e recredenciamento das Instituições e o reconhecimento de cursos. Além de especificar as atribuições do Conselho (e da Câmara de Educação Superior), também mudaram as funções do próprio Ministério da Educação, que passou a "[...] (BRASIL, 1995, art. 1).

A normativa anunciou a centralidade da avaliação no governo FHC, estabelecendo a sistemática da avaliação, prenunciando a LDB e as políticas posteriores para a educação superior. Dispôs que o Ministério: "[...] fará realizar avaliações periódicas das instituições e dos cursos de nivel superior, fazendo uso de procedimentos e critérios abrangentes dos diversos fatores que determinam a qualidade e a eficiência das atividades de ensino, pesquisa e extensão (art. $3^{\circ}$ )". Na lei, definiu-se que seria obrigatória a realização de exames nacionais.

0 governo FHC realizou uma redistribuição de funções no próprio Ministério, especialmente na SESu, apesar das críticas à burocracia estatal realizadas pelos defensores da reforma gerencial divulgadas na época ${ }^{6}$. Ainda, reformulou o papel do

\footnotetext{
${ }^{5}$ No governo Itamar Franco, pela Medida Provisória 661 de 18/10/1994. Sobre a diminuição dos poderes do CNE, ver Souza, (2001) e Neves (2002).

${ }^{6}$ A posição norteadora desse momento é a de Bresser Pereira (1998).
} 
INEP, transformando-o numa autarquia ${ }^{7}$, e acrescentando às suas atividades tradicionais de documentação o desenvolvimento de sistemas de avaliação da educação básica e superior e, especificamente, a coordenação do processo de avaliação dos cursos de graduação (Art. $1^{\circ}$ Inciso $\mathrm{VI}$ ).

Ao contrário do acontecido em outras áreas, não houve nem a criação de uma agência reguladora, nem de uma agência de garantia de qualidade nem de um sistema articulado de avaliação. Houve apenas a distribuição das ações avaliativas e regulatórias nos diversos órgãos do Ministério: CNE, SESu e INEP.

Retomando a questão de quem tem a responsabilidade de definir os padrões de qualidade, é conveniente lembrar que, no início da gestão Paulo Renato de Souza, no Ministério da Educação, houve forte resistência da comunidade acadêmica à implantação de procedimentos de avaliação que tinham como base a realização de provas pelos formandos. Nesse contexto de confronto e de fortalecimento do MEC na regulação da Educação Superior, em 1997, o Ministro baixou a Portaria 879 prevendo que a qualidade da educação superior seria determinada pelas Comissões de Especialistas ${ }^{8}$, tendo como fundamento um decreto presidencial de 1985.

Visando a compreender o papel que essas Comissões tiveram na definição nos padrões de qualidade da educação superior, retomar-se-á, aqui, o histórico das normas legais a elas relativas.

Em 1985, o então Presidente da República José Sarney estabeleceu por decreto o funcionamento das Comissões de Especialistas (BRASIL, 1985). Na exposição de motivos do Decreto apontou-se que essas comissões teriam papel relevante na constituição de um sistema de avaliação do ensino profissional e científico. As comissões teriam o apoio financeiro e administrativo da Secretaria de Educação Superior do Ministério da Educação. Ao Ministério coube estabelecer as atribuições, os mandatos e os membros das Comissões. Este decreto estava afinado com o relatório em elaboração pela Comissão Nacional de Reformulação da Educação Superior, no qual, tomando como modelo os procedimentos da CAPES na avaliação da Educação Superior, defendia-se que a avaliação só seria legítima se fosse conduzida pelos pares acadêmicos.

As Comissões teriam o papel de assessorar o Ministério na elaboração dos processos de avaliação dos cursos que seriam instituídos e cumpririam o papel de assessoria técnica na aferição da qualidade da educação superior ${ }^{9}$. Nesse momento,

\footnotetext{
7 Pela Medida Provisória 1.568 de 14 de fevereiro de 1997, convertida pelo Congresso Nacional na Lei 9.448 (BRASIL, 1997a).

8 Os "especialistas" respondem à modalidade da "avaliação por pares" amplamente utilizada e reconhecida no âmbito acadêmico. É a lógica da avaliação acadêmica aplicada à avaliação da academia.

${ }_{9}^{9}$ Ver a Portaria $n^{\circ}$ 706, de 5 de setembro 1985, que regulamentou o Decreto supracitado.
} 
não houve menção à definição de padrões de qualidade. Em 1986, foi criada a Secretaria Executiva das Comissões de Especialistas, com a função de administrar os trabalhos realizados pelas Comissões ${ }^{10}$.

Em 1992, a Secretaria de Educação Superior (SESu) instituiu as Comissões de Especialistas ${ }^{11}$. Comparando-a com as Portarias anteriores, ela manteve a mesma incumbência de assessorar a instalação de um processo permanente de avaliação, aumentou o vínculo das comissões com a SESu e as subordinou a esta, e, pela primeira vez, apresentou como responsabilidade das Comissões, a prescrição de padrões mínimos de qualidade. Em 1993, instituiu-se uma Comissão para estabelecer "diretrizes e viabilizar a implantação do processo de avaliação institucional nas universidades brasileiras"12, iniciando o processo para a criação e institucionalização do Programa de Avaliação Institucional das Universidades Brasileiras (PAIUB) ${ }^{13}$. É relevante observar que:

a) foi a primeira vez que, nas Portarias, se utilizou o termo "avaliação institucional";

b) foi prevista a continuidade do trabalho das Comissões de Especialistas e a articulação entre elas e a Comissão criada pela portaria;

c) foi atribuído à Comissão o papel de estabelecer diretrizes para o processo de avaliação;

d) não foi mencionada a definição de padrões de qualidade.

Dando continuidade a esse processo, no governo Fernando Henrique, as Comissões de Especialistas exerceram papel central no processo de autorização e reconhecimento de cursos no modelo implantado por meio do Exame Nacional de Cursos. Em 1997, o trabalho das Comissões foi novamente regulamentado por Portaria ${ }^{14}$.

Art. $1^{\circ}$. As comissões de especialistas de ensino têm como objetivo assessorar a Secretaria de Educação Superior do Ministério da Educação e do Desporto nas seguintes ações:

l-analisar e verificar in loco o mérito das propostas de autorização de novos cursos e credenciamento de faculdades integradas, faculdades, institutos superiores ou escolas superiores, nos termos das Portarias 640 e 641 de 1997;

\footnotetext{
${ }^{10}$ Portaria MEC/SESu 25, de 27 de fevereiro de 1986, que foi substituída pela Portaria 509 de 30 de setembro de 1987. Na edição desta Portaria, não foi alterado substancialmente o conteúdo da anterior, havendo apenas a explicitação sobre o mandato dos membros das comissões

11 Portaria SESu 287 de 10 dezembro de 1992.

12 Portaria SESu/MEC 130 de 14 de julho de 1993 (art $1^{\circ}$ ).

${ }^{13}$ O PAIUB foi instituído pela Portaria 1.855 de 30 de dezembro de 1994.

${ }^{14}$ Portaria no 879 (BRASIL, 1997b), sendo substituída pela Portaria 972 (BRASIL, 1997c). Observa-se que a Portaria no 879 teve como fundamentação legal os Decretos 91.607 (BRASIL, 1985), que instituiu as Comissões de Especialistas - e o 2.207/1997 - que regulamentava o Sistema Federal de Ensino, enquanto que a Portaria no 972 (BRASIL, 1997c) só foi fundamentada no segundo Decreto citado.
} 
II-atualizar, periodicamente, os critérios de qualidade e indicadores de oferta e demanda para os cursos da área de atuação;

III - propor diretrizes e organização curriculares das respectivas áreas;

$I V$ - verificar in loco as condições de funcionamento das instituições e dos cursos de nivel superior, inclusive para fins de seu reconhecimento, sempre que solicitadas pela Secretaria de Educação Superior do MEC;

$V$ - opinar, mediante solicitação da Secretaria de Educação Superior, em assuntos de sua especialidade. (BRASIL, 1997c).

Esse processo de elaboração de normas trouxe para o âmbito do Ministério da Educação $0^{15}$ a prerrogativa de definir o que é a qualidade da educação superior e os seus indicadores, consequentemente, ao MEC coube a responsabilidade de regulamentar, via definição de padrões, a organização das IES. Contudo, a definição do que seria a qualidade não foi centralizada dentro do Ministério, isto é, as diversas comissões de especialistas das várias áreas definiam isoladamente o que seria a qualidade para os seus cursos, processo que se assemelhava ao realizado pela CAPES na avaliação da pós-graduação. A diversidade de definições ocorria tanto na realização do Exame Nacional de Cursos, como na Avaliação das Condições de Oferta ${ }^{16}$.

Em 2001, foi baixado outro Decreto (BRASIL, 2001) alterando a regulamentação do Sistema Federal de Ensino. Esse previu a coordenação da avaliação pelo Ministério da Educação e a organização, bem como a execução, pelo INEP. Como organizador e executor da avaliação, o INEP, entre os anos de 2001 e 2002, elaborou os manuais para a avaliação das Instituições e dos cursos de graduação. Dessa forma, ao definir os indicadores de qualidade e os instrumentos para a sua avaliação, o Instituto, por delegação do Ministério, definiu os padrões de qualidade para a educação superior. Nos documentos oficiais, observa-se a busca de legitimação dessas definições. Em geral, há dois movimentos de legitimação: a) nos manuais, afirma-se que o material foi resultado de estudos realizados pela Diretoria de Estatísticas e Avaliação da Educação Superior (DAES) do INEP e por jornadas nas quais se contou com a participação de professores de instituições públicas e privadas; b) o Instituto submeteu os Manuais ao Conselho Nacional de Educação, apesar de esse encaminhamento não ser previsto na legislação ${ }^{17}$.

\footnotetext{
${ }^{15} 0$ Ministério da Educação possui uma estrutura organizacional composta de: a) órgãos de assistência direta e imediata ao Ministro de Estado, b) órgãos especificos singulares (secretarias que tratam dos diferentes níveis e modalidades educativos, c) um órgão colegiado: o Conselho Nacional de Educação; e d) autarquias, dentre as quais o Instituto Nacional de Estudos e Pesquisas Educacionais "Anísio Teixeira", além de outros institutos e instituições (BRASIL, 2003b).

${ }^{16}$ Sobre a diversidade de padrões de qualidade e de indicadores ver o Parecer CNE/CSE 1070 (BRASIL, 2000)999, Rothen (2002), Meneghel e Bertolin (2003, p. 116).

${ }^{17}$ Ver os Pareceres do CNE/CSE 1.366 (BRASIL, 2001), (BRASIL, 2002), 267 (BRASIL, 2002).
} 
Em síntese, no governo Fernando Henrique Cardoso, a definição dos padrões de qualidade foi, em um primeiro momento, responsabilidade de uma Secretaria, a SESu, e, num segundo momento, quando da avaliação in loco de cursos e instituições, de uma autarquia dependente do Ministério, o INEP, que também passou a definir os padrões de qualidade; e, quando da aplicação do Exame Nacional de Cursos continuou sendo prerrogativa das Comissões de Especialistas, elaboradoras das Portarias que recebiam a assinatura do Ministro da Educação.

A dinâmica descrita aponta que, no caso brasileiro da implantação da reforma da autonomia avaliada, verificou-se como uma das suas dificuldades a questão da legitimidade para definir o que seria qualidade. Em outras palavras, ao centralizar-se no Ministério da Educação a prerrogativa de apontar as Instituições que atenderiam aos padrões mínimos, tendo como base as comissões de especialistas e o Conselho Nacional de Educação, construiu uma rede de sustentação visando a obter autoridade acadêmica/técnica para constituir-se em uma peça importante do Estado Avaliador.

\section{Primeiro Governo Lula}

No primeiro governo Lula (2003-2006), em geral, as agências reguladoras não ganharam adeptos, pelo contrário, foram questionadas, no início, para depois continuarem com suas funções, com poucas mudanças (NUNES, 2005, p. 12). No que diz respeito à educação superior, as tendências esboçadas no governo anterior se aprofundaram. Os órgãos do Ministério da Educação continuaram com suas funções, que foram reforçadas: a SESu, com o novo Departamento de Supervisão do Ensino Superior (BRASIL, 2003b), com algumas funções similares às do $\mathrm{CNE}^{18}$, tendo também as da organização e coordenação de atividades de comissões designadas para ações de supervisão do ensino superior.

A criação do Sistema Nacional de Avaliação da Educação Superior (SINAES) (BRASIL, 2004b) mostra a manutenção da avaliação da educação superior como uma política privilegiada, contudo não mais central. Se, no governo anterior, uma sucessão de atos normativos criou o Exame Nacional de Cursos (ENC), também conhecido como Provão e outros instrumentos, no governo Lula, foi promulgada uma lei, após longo processo nos bastidores do governo, finalmente aprovada pelo Congresso.

Com o SINAES, foi instituída a avaliação em três instâncias: instituição, curso e estudantes. Uma das diferenças do SINAES é de que na legislação foi previsto que as três instâncias não seriam independentes, para que as informações fossem mais completas. A finalidade declarada da avaliação seria a melhoria da qualidade, ressaltando a missão pública da educação superior (BRASIL, 2004b). Seus resultados ainda seriam "[...] referencial básico dos processos de regulação e supervisão da educação superior", definindo

\footnotetext{
${ }^{18}$ Decreto no. 4.791, (BRASIL, 2003b), Art. $18^{\circ}$ do Anexo I, inciso III, "diretrizes e instrumentos para credenciamento e recredenciamento de IES, autorização, reconhecimento e renovação de reconhecimento de cursos superiores".
} 
tais processos como "de credenciamento, sua renovação, a autorização, o reconhecimento e a renovação de reconhecimento de cursos de graduação" (BRASIL, 2004b). Com o SINAES, objetivou-se separar a avaliação da regulação, embora a primeira seja 0 elemento que fundamenta a segunda (BARREYRO; ROTHEN, 2006, p. 967-968).

\section{A definição da qualidade}

Na proposta do SINAES, a questão da qualidade foi mencionada como objetivo principal do sistema ("melhoria da qualidade"), mas não claramente definida, permanecendo como um conceito impreciso e, às vezes, contraditório.

A Lei $n^{\circ}$. 10.861 (BRASIL, 2004b), aprovada pelo Congresso e promulgada pelo Presidente da República, estabeleceu as dimensões para a avaliação de instituições, cursos e estudantes. Ao prever as dimensões da avaliação em cada um dos eixos (instituições, cursos e estudantes), o Congresso Nacional definiu os padrões de qualidade.

Para a avaliação institucional foram definidas dez dimensões (BRASIL, 2004b, art. $3^{\circ}$ ), a avaliação de cursos realizada pelo perfil do corpo docente, instalações fisicas e organização didático-pedagógica (BRASIL, 2004b, art. $4^{\circ}$ ), conforme estabelecido na Avaliação das Condições de Ensino (ACE) no governo FHC. Quanto ao Exame Nacional de Desempenho dos Estudantes (ENADE), a lei determinou que o conteúdo, as habilidades e as competências avaliados seriam os expressos nas diretrizes curriculares (BRASIL, 2004b, art.5ํ. \$1). Ressalta-se, aqui, que as diretrizes foram estabelecidas pelo Conselho Nacional de Educação paulatinamente, após a promulgação da LDB (BRASIL, 1996). Na lei, ainda foi previsto que os conceitos seriam ordenados em uma escala utilizando como referência os "[...] padrões mínimos definidos por especialistas das diferentes áreas do conhecimento" (BRASIL, 1996, Art. 5, § 8º. Na regulamentação da lei definiu-se que seriam avaliados os alunos do final do primeiro e do último ano dos cursos e que o INEP seria o responsável pela definição dos "[...] critérios e procedimentos técnicos para a aplicação do Exame".

Na prática, na implantação do ENADE, os especialistas estabelecem os conteúdos das provas, segundo as Diretrizes Curriculares Nacionais; por outro lado, apesar da previsão de que a escala de valores seria determinada a partir de padrões mínimos definidos pelos especialistas de cada área, na prática essa foi realizada, em dois momentos, pela Diretoria de Estatística e Avaliação da Educação Superior do INEP. a) $\mathrm{Na}$ apresentação dos resultados relativos ao ENADE de 2004 (INEP, 2004), foi estabelecido como critério o conceito estatístico "afastamento padronizado" (AP). b) Na divulgação dos resultados do ENADE de 2005 foi inserida mais uma ferramenta estatística a partir da qual se definem os padrões mínimos: o "Indicador de Diferença entre os Desempenhos Observados e Esperados" (IDD). ${ }^{19}$

\footnotetext{
${ }^{19}$ Nos Relatórios-sinteses desse ano não é apresentado o conceito do IDD, este sendo encontrado apenas no relatório específico de cada curso. Por exemplo, no Relatório do curso de Pedagogia, da Universidade Católica de Pelotas, define-se que o "IDD é a diferença entre o desempenho médio do concluinte de um curso e o desempenho médio estimado para os concluintes desse mesmo curso".
} 
Um novo órgão foi criado em 2004: a Comissão Nacional de Avaliação da Educação Superior (CONAES), com funções de coordenação e supervisão do SINAES. Diferentemente de outras agências similares, desenvolvidas em outros paises (RAMA, 2006, p.151-152), ela não é independente do governo, faz parte dele (está vinculada ao Gabinete do Ministro)enão é uma agência de garantia da qualidade e nem uma agencia reguladora; não é executora de avaliações e nem exerce a regulação; é uma comissão que assessora sobre questões técnicas de avaliação: especialmente, emite diretrizes (para realização dos instrumentos a serem utilizados e para seleção de avaliadores que realizam avaliações externas). Em 2006, foi-lhe atribuida a função de estabelecer diretrizes para a constituição e manutenção do banco público de avaliadores especializados (BRASIL, 2006a), assunto que será tratado adiante.

Na definição das competências da CONAES, uma das suas atribuições é "propor e avaliar as dinâmicas, procedimentos e mecanismos da avaliação institucional, de cursos e de desempenho dos estudantes" (BRASIL, 2004a, art $6^{\circ}$, Inc. I). Em um primeiro momento a CONAES, baseada nos padrões de qualidade determinados em lei, assumiu a responsabilidade de desenvolver os indicadores de qualidade que seriam considerados na avaliação. Isto foi realizado em diversos documentos, mas em cada um deles a questão da qualidade foi tratada de maneira distinta. Nos dois primeiros - Diretrizes para a avaliação das Instituições de Educação Superior (2004a) e o Roteiro de Autoavaliação institucional (INEP, 2005), a autoavaliação institucional é o pilar basilar das avaliações e, coerentemente com a visão emancipatória da avaliação, caberia a cada IES definir os indicadores de qualidade. No texto Avaliação Externa de Instituições de Educação Superior: diretrizes e instrumento (BRASIL, 2005), defendeu-se que existiriam dois tipos de padrões: os particulares, fixados pela IES, e os universais fixados no documento; na sequência foram apresentados uma gama de indicadores e o peso de cada um deles na avaliação externa das Instituições.

Em janeiro e fevereiro de 2006, o Ministro da Educação baixou portarias aprovando o "Instrumento de Avaliação Externa de Instituições" (BRASIL, 2006b) e o "Instrumento de Avaliação Externa dos Cursos de Graduação" (BRASIL, 2006c), utilizando como fundamentação a Lei do SINAES e a Lei que aprovou o Plano Nacional de Educação. ${ }^{20}$ As Portarias não fazem referência ao órgão responsável pela elaboração dos instrumentos, a CONAES/INEP.

Com a implantação do SINAES, uma parte da definição dos padrões de qualidade foi determinada por atos normativos do Congresso (lei) e do Conselho Nacional de Educação (diretrizes curriculares) e outra parte ficou sob a responsabilidade de uma agência de assessoramento (CONAES), uma autarquia (INEP) e dos especialistas das áreas. A publicação de documentos antagônicos pela CONAES e pelo INEP evidencia a não neutralidade técnica da avaliação e, principalmente, que é problemática a legitimação da definição do que é qualidade da educação superior por esta via técnica.

${ }^{20}$ Lei no 10.172 (BRASIL, 2001), no seu art. 4 prevê que "A União instituirá o Sistema Nacional de Avaliação" 


\section{Decreto Ponte}

Dois anos após a sanção da lei que estabeleceu o SINAES, o Ministério colocou em consulta pública um decreto que revogava algumas normas anteriores, sintetizando e definindo os eixos da regulação do sistema. Na promulgação, o Decreto $n^{\circ}$. 5.773 (BRASIL, 2006a) foi chamado pelo Ministério de "ponte", com a afirmação de que ele articularia a avaliação com a regulação. Esse Decreto explicita procedimentos que atenderiam às funções de regulação, supervisão e avaliação das Instituições e Cursos. Assim, segundo o Decreto, a regulação seria efetuada "por meio de atos administrativos autorizativos do funcionamento de instituições e cursos [...]" (BRASIL, 2006a, art.1ํ, §1). A supervisão seria realizada para "zelar pela conformidade da oferta de educação superior com a legislação aplicável" (BRASIL, 2006a, art.1ํ, §2), ou seja, o controle do cumprimento das normas. Já a avaliação seria "referencial básico para os processos de regulação e supervisão da educação superior" para promover a melhoria de qualidade (BRASIL, 2006a, art.1º, \$3).

A definição dos parâmetros de qualidade, no Decreto Ponte, deu ênfase para os órgãos do Ministério, embora com a participação das diversas instâncias. As ações são de dois tipos básicos: a) para o credenciamento de Instituições e autorização de Cursos; b) para o processo de avaliação do SINAES, que é referencial básico para o recredenciamento de Instituições e reconhecimento e renovação de reconhecimento de Cursos.

No primeiro tipo (BRASIL, 2006a, art. 4º), é de competência das Secretarias do Ministério (de Educação Superior, de Educação Profissional e Tecnológica, de Educação a Distância) propor ao CNE diretrizes para que o INEP elabore instrumentos de avaliação para o credenciamento de Instituições, que são, depois, aprovados pelo CNE. A essas Secretarias compete, ainda, elaborar as diretrizes para a autorização

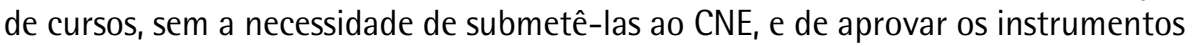
de avaliação elaborados pelo INEP. Em todos os casos, é competência do Ministro homologar os instrumentos de avaliação.

No segundo tipo, os padrões de qualidade utilizados nas avaliações realizadas pelo SINAES são elaborados pela CONAES, que estabelece as diretrizes para a criação dos Instrumentos. Após a elaboração dos instrumentos pelo INEP, essa Comissão os aprova e encaminha-os para a homologação do Ministro (BRASIL, 2006a, art.8º).

A sanção do Decreto-Ponte foi, por um lado, uma tentativa de diminuir a enorme quantidade de normas promulgadas por diversos órgãos do Ministério, desde 1997, concentrando os procedimentos num único ato legislativo; bem como, uma tentativa de resolução das contradições evidenciadas entre o Roteiro de Autoavaliação institucional e o Instrumento de Avaliação Externa de Instituições, ao determinar a participação de cada uma das instâncias que, futuramente, interviriam na definição das diretrizes para construção de instrumentos de avaliação. Por outro 
lado, colocou um véu sobre quem é que define a qualidade, pois, como vimos acima, alguns meses antes do Decreto-Ponte o Ministério da Educação já tinha aprovado os instrumentos da Avaliação Externa de Instituições e de Graduação.

\section{Comissão Técnica de Acompanhamento da Avaliação (CTAA)}

Sete dias depois de aprovado o Decreto-Ponte - que especificou a função de todos os órgãos envolvidos e em que não estava prevista a intermediação de nenhuma comissão técnica -, criou-se mais uma comissão, a Comissão Técnica de Acompanhamento da Avaliação (CTAA) ${ }^{21}$; na mesma Portaria foi prevista a instalação do Banco de Avaliadores do Sistema Nacional de Avaliação da Educação Superior (BASis).

Essa nova comissão conta com três representantes do INEP, um da CAPES, dois da CONAES, um da SESu, um da SETEC, um da Secretaria de Educação a Distância do MEC e dezesseis docentes de diferentes áreas do conhecimento, com experiência em avaliação ou gestão da educação superior, com "notória competência científico-acadêmica"22.

A CTAA tem a função de acompanhar os trabalhos das comissões de especialistas, julgar os recursos advindos das avaliações externas (institucional e de cursos) e selecionar os avaliadores que realizarão visitas de avaliação in loco. À diferença da CONAES, que também é uma comissão técnica, profissional, a CTAA tem um perfil mais operacional do que aquela. Enquanto a CONAES assessora o Ministro, realiza convênios com os sistemas estaduais e estabelece diretrizes, a CTAA supervisiona o trabalho das comissões e pode julgar recursos decorrentes das avaliações externas.

A coexistência de duas comissões para tratar da avaliação da educação superior teve um antecedente efêmero: na Medida Provisória no. 147 (BRASIL, 2003c), o então Ministro Cristóvam Buarque criou a Comissão Nacional de Avaliação e Progresso do Ensino Superior (CONAPES) e a Comissão Nacional de Orientação da Avaliação (CONAV), com funções similares às da CTAA e da CONAES. No processo de conversão dessa medida provisória para a Lei nº 10.861 (BRASIL, 2004b), que instituiu o SINAES, ambas desapareceram, sendo criada a CONAES atual.

Tanto a CONAES quanto a CTAA são comissões que têm bastante representação governamental, além de que a nomeação dos membros não governamentais é prerrogativa do Presidente e do Ministro. A criação da nova Comissão, de certa forma, influi na operacionalização da avaliação, mas, por enquanto, não teve influência na determinação dos padrões de qualidade da educação superior.

${ }^{21}$ Portaria $n^{0}$. 1.027/06. de 15 de maio de 2006.

${ }^{22}$ Portaria $n^{\circ}$. 1027/06, art. $7^{\circ}$ 


\section{Especialistas}

$\mathrm{Na}$ avaliação da educação superior, os especialistas cumpriam, no governo Fernando Henrique Cardoso, um papel importante na definição de critérios para elaboração de instrumentos de avaliação visando ao credenciamento de instituições e à avaliação dos cursos, da mesma forma como atuavam para determinar as diretrizes por áreas do Provão. As "visitas por comissões de especialistas", para a realização de avaliações externas eram uma sistemática frequentemente utilizada e foi mantida no SINAES (BRASIL, 2004b, art. $4^{\circ}, \S 1$ ), e, formalmente, para o estabelecimento de padrões mínimos do ENADE (BRASIL, 2004b, art. 50, § 8) ${ }^{23}$.

Entre 2004 e 2006, houve a edição de seis Portarias e uma Resolução ministeriais ${ }^{24}$ que tratam dos especialistas. Nelas, eram estes requeridos e nomeados para três funções: a) realizar avaliações in loco; b) compor comissões de avaliação institucional para criação do Instrumento de avaliação externa de instituições ${ }^{25}$; c) compor comissões de especialistas de cursos para estabelecer as diretrizes das provas do ENADE.

Em 2006, foi criado o Banco de Avaliadores do Sistema Nacional de Avaliação da Educação Superior (BASis), com a finalidade de "[...] aumentar a participação da comunidade acadêmica no acompanhamento dos processos de avaliação das instituições de educação superior e dos cursos de graduação" ${ }^{26}$, sob responsabilidade do INEP. O BASis é um cadastro de avaliadores selecionados para realizar os processos de avaliação in loco dos cursos e instituições do SINAES, indicados por diversas entidades ou com livre inscrição do candidato, que cumprem requisitos pré-estabelecidos de perfil profissional, acadêmico e ético. Eles são previamente capacitados para depois comporem comissões de avaliação externa in loco.

Em sintese, no governo Lula, na definição dos padrões de qualidade, os especialistas em diversas áreas do conhecimento acabaram sendo substituídos por agências profissionais de avaliação, em outras palavras, por especialistas em avaliação que participam dessas agências (Inep, CONAES, Secretarias do Ministério, Conselho Nacional de Educação). A nova legislação continuou com o procedimento instituído no governo anterior quanto a manter os processos de avaliação e regulação no órgão ministerial. O INEP continuou como autarquia, com destaque para a divulgação de informações e estatísticas educacionais e ênfase na avaliação (BRASIL, 2003a) e, depois da sanção da lei do SINAES, reafirmou sua identidade como realizador de avaliações, concentrando todos os procedimentos avaliativos (instituições, cursos e estudantes, e os fins: entrada ou permanência no sistema) ${ }^{27}$.

\footnotetext{
${ }^{23}$ Como vimos acima, os padrões mínimos foram definidos pelo INEP e os conteúdos. Habilidades e Competências tomam como referência as Diretrizes Curriculares

${ }^{24}$ Portaria MEC 4.362, de 29/12/2004, Portaria MEC 2.051/04, art. 13; Resolução CNE/CES nº 1 de 4/5/2005, Portaria MEC 1.027 de 15/05/2006, Portaria MEC 1.751 de 27/10/2006, Portaria INEP 106/04, Portaria MEC 1.310, de 17/07/2006.

${ }^{25}$ Portaria $n^{0} .106 / 04$, art. 2.

${ }^{26}$ Portaria 1.027 de 15/5/2006.

${ }^{27}$ Inclusive os que anteriormente eram realizados pelas secretárias do MEC (Sesu, SETEC) para entrada no sistema.
} 


\section{Considerações finais}

Comparativamente a outros paises da América Latina, o Brasil está desenvolvendo a avaliação da educação superior com características do que Rama (2006, p.3691) chama de segunda e terceira reformas, isto é: há uma forte expansão interna da educação superior, via iniciativa privada, e segue-se a tendência internacional de controle da qualidade do sistema, isso, apesar de, até o momento, não haver tanta influência direta da internacionalização, na educação superior, brasileira.

Durante o governo FHC, foi iniciado o processo de avaliação da educação superior com a sua função relacionada com a qualidade do sistema. Verificou-se uma perda de funções do CNE para os órgãos específicos do Ministério. Em um primeiro momento, as comissões de Especialistas vinculadas à SESu determinavam o padrão de qualidade e, em um segundo momento, o INEP passou também a defini-lo.

No governo Lula, no que diz respeito à avaliação, apesar de diversos momentos de hesitação, ela ganhou relevo. Seja pelo desenvolvimento de um modelo de avaliação mais complexo, seja pela sua autonomia em relação à regulação, que derivou na criação de uma comissão, a CONAES, em 2004, com função técnico-acadêmica: orientar as avaliações.

A regulação do sistema foi normatizada em 2006, no último ano do primeiro governo Lula, a partir da sanção do Decreto-Ponte. Os órgãos de regulação continuam os mesmos que no governo $\mathrm{FHC}$ e não há reversão nas funções do CNE, mas há uma divisão de tarefas mais clara e mais marcada entre a SESu e o INEP.

Assim, a avaliação da educação superior e a definição dos padrões de qualidade têm ganho institucionalização mediante leis federais, aprovadas pelo Congresso e sancionadas pelo Presidente.

Para a definição dos padrões de qualidade da Educação Superior, ganhou-se mais uma agência, a CONAES e, posteriormente, mais uma comissão, a CTAA. Finalmente, foi criado o BASis para a execução das avaliações. Todas essas instâncias encontram-se na estrutura do Ministério da Educação.

Em nivel ministerial, com a criação das agências (CONAES, CTAA) e do BASis, continua a tendência à participação dos acadêmicos na concepção, monitoramento e execução da avaliação da educação superior. Assim, embora os especialistas tenham sido atores importantes desde a década de 80 , há, na avaliação, uma maior institucionalização dessa participação. Essa tendência de utilização de especialistas é uma estratégia de legitimação visando a outorgar credibilidade ao processo pelos atributos da profissionalização e da especialização. A CONAES é um ente formal que dá legitimidade à avaliação, não tendo funções executivas, sendo um órgão consultivo, composto por especialistas do campo do saber universitário, visando também à legitimidade. 
A escolha de especialistas, professores de Instituições de Educação Superior é uma forma de legitimação da avaliação externa das instituições (pelo Estado), especialmente daquelas que gozariam de autonomia (as universidades) A evolução dessa convocatória aos especialistas, durante o período estudado, por meio da institucionalização, seja da CONAES, seja do BASis buscou a legitimidade do processo.

0 fato de não se ter constituído uma agencia reguladora ou uma agência de avaliação foi devido à "suspeita social" de que têm sido alvos instituições como o Conselho Federal de Educação (no passado) e o Conselho Nacional de Educação (nos tempos recentes e atuais) na sociedade brasileira. Por isso, o "Estado burocrático", apesar das críticas e embates sofridos, foi reforçado pela criação das citadas comissões (CONAES, CTAA, BASis).

A contínua mudança de órgãos responsáveis pela definição dos padrões de qualidade e a participação de tantas agências, além da busca de legitimação pelo conhecimento técnico dos especialistas, revela o embate político em torno da definição do que seria qualidade na educação superior brasileira.

No caso brasileiro, também, aplica-se a reflexão de Fernandez Lamarra (2007, p. 41) segundo a qual, mais do que uma definição do que seja qualidade, o processo analisado mostra mudanças e redefinições acerca de quem determina os padrões, isto é, nesse caso, chegando à participação de quase todas as instâncias do MEC nessa tarefa de definição de diretrizes para construir instrumentos.

Essas mudanças no aparelho do Estado permitem verificar no Brasil o percurso da segunda para a terceira reforma (RAMA, 2006, p. 36-91): a regulação pública aferindo a qualidade do sistema, assim como a volta à educação como bem público, o que se verificaria no SINAES.

No caso brasileiro da reforma, a determinação de quem define os padrões de qualidade é sintomática da armadilha que se construiu ao tentar avaliar/regular a educação superior prioritariamente a partir de demandas externas à educação.

Mas, esse processo parece ainda inacabado, haja vista as novas mudanças implantadas na avaliação da educação superior ${ }^{28}$, recentemente, no segundo governo Lula, que alteram significativamente o SINAES, evidenciando um modelo ainda em definição e, inclusive, a priorização do tema no Plano de Desenvolvimento da Educação que expressa as diretrizes governamentais de política educacional para o segundo mandato.

\footnotetext{
${ }^{28}$ Tais como: a desconsideração e/ou minimização de dois instrumentos do SINAES; a) a avaliação institucional e a avaliação de cursos pela utilização do IGC (Indice Geral de Cursos), b) a indução do ranqueamento das Instituições, levanto em conta os resultados desse indice, c) o sobre-dimensionamento dos resultados do exame ENADE para compor esses indices. (Portaria Normativa MEC $n^{\circ}$ 4/08; Portaria Normativa MEC $n^{\circ}$ 12/08).
} 


\section{Referências}

BARREYRO, G.; ROTHEN, J. C. Avaliação e regulação da Educação Superior: normativas e órgãos reguladores nos 10 anos pós LDB. Avaliação, Campinas, v. 12, p. 133-144, mar. 2007.

. "SINAES" contraditórios: considerações sobre a elaboração e implantação do Sistema Nacional de Avaliação da Educação Superior. Educação \&t Sociedade, Campinas, v. 27, n. 96, p. 955-977, 2006. Especial.

BRASIL. Comissão Nacional de Avaliação da Educação Superior. Instituto Nacional de Estudos e Pesquisas Educacionais Anísio Teixeira. Avaliação externa de instituições de educação superior. diretrizes e instrumento. Brasilia, DF, 2005. Disponivel em:<http://www.inep.gov.br/download/superior/2005/ avaliacao_institicional/avaliacao_institucional_externa_8102005.pdf >. Acesso em: 12 nov. 2009.

BRASIL. Comissão Nacional de Avaliação da Educação Superior. Instituto Nacional de Estudos e Pesquisas Educacionais Anísio Teixeira. Diretrizes para a avaliação das Instituições de Educação Superior. Brasília, DF, 2004a. Disponível em: <http:// www.metodista.br/avaliacao-institucional/documentos/conaes.pdf>. Acesso em: nov. 2005.

BRASIL. Decreto n 4.633, de 21 de março 2003. Aprova a estrutura regimental e o quadro demonstrativo dos cargos em comissão e das funções gratificadas do Instituto Nacional de Estudos e Pesquisas Educacionais Anísio Teixeira, e dá outras providências. Diário Oficial [da República Federativa do Brasil], Brasilia, DF, 24 mar. 2003a. Disponivel em: < http://www.planalto.gov.br/ccivil_03/Decreto/2003/ D4633.htm>. Acesso em: 24 nov. 2009.

BRASIL. Decreto no 4.791, de 22 de julho de 2003. Aprova a estrutura regimental e o quadro demonstrativo dos cargos em comissão e das funções gratificadas no Ministério da Educação e dá outras providências. Diário Oficial [da República Federativa do Brasil], Brasilia, DF, 23 jul. 2003b. Disponivel em: <http:// www.planalto.gov.br/ccivil_03/Decreto/2003/Ret/retdec4791-03.pdf>. Acesso em: 24 nov. 2009.

BRASIL.. Decreto $n^{\circ} 5.773$, de 9 de maio de 2006. Dispõe sobre o exercício das funções de regulação, supervisão e avaliação de instituições de educação superior e cursos superiores de graduação e seqüenciais no sistema federal de ensino. Diário Oficial [da República Federativa do Brasil], Brasília, DF, 10 maio 2006a. Disponivel em: <http://www.planalto.gov.br/ccivil_03/_ato2004-2006/2006/ Decreto/D5773.htm>. Acesso em: 24 nov. 2009. 
BRASIL. Decreto no 91.607, de 3 de setembro 1985. Institui Comissões de Especialistas para consultoria e assessoramento em matéria de avaliação e qualificação da educação superior. Legislação, Brasilia, DF, 3 set. 1985,. Disponível em: <http://www6.senado.gov.br/legislacao/ListaPublicacoes.action?id=219027>. Acesso em: 26 nov. 2009.

BRASIL. Lei $n^{\circ} 9.131$, de 24 de novembro 1995. Altera dispositivos da Lei $n^{\circ}$ 4.024, de 20 de dezembro de 1961, e dá outras providências. Diário Oficial [da República Federativa do Brasil], Brasilia, DF, 25 nov. 1995. Disponivel em: <http:// www.planalto.gov.br/ccivil/leis/L9131.htm>. Acesso em: 24 nov. 2009.

BRASIL. Lei no 9.394, de 20 de dezembro de 1996. Estabelece as diretrizes e bases da educação nacional. Diário Oficial [da República Federativa do Brasil], Brasília, DF, 23 dez. 1996. Disponível em: < http://portal.mec.gov.br/arquivos/pdf/ diretrizes.pdf>. Acesso em: 12 nov. 2009.

. Lei $n^{\circ}$ 9.448, de 14 de março 1997. Transforma o Instituto Nacional de Estudos e Pesquisas Educacionais - INEP em Autarquia Federal, e dá outras providências. Diário Oficial [da República Federativa do Brasil], Brasilia, DF, 15 mar. 1997a. Disponivel em: < http://www.planalto.gov.br/ccivil_03/LEIS/ L9448.htm>. Acesso em: 25 nov. 2009.

. Lei no 10.172, de 9 de janeiro 2001. Aprova o Plano Nacional de Educação e dá outras providências. Diário Oficial [da República Federativa do Brasil], Brasilia, DF, 10 jan. 2001. Disponivel em: < http://www.planalto.gov.br/ ccivil_03/LEIS/LEIS_2001/L10172.htm >. Acesso em: 25 nov. 2009.

. Lei $n^{0}$ 10.861, de 14 de abril 2004. Institui o Sistema Nacional de Avaliação da Educação Superior - SINAES e dá outras providências. Diário Oficial [da República Federativa do Brasil], Brasilia, DF, 15 abr. 2004b. Disponivel em: $<$ http://www.planalto.gov.br/ccivil_03/_Ato2004-2006/2004/Lei/L10.861.htm>. Acesso em: 25 nov. 2009.

BRASIL. Medida Provisória n 147, de 15 de dezembro 2003. Institui o Sistema Nacional de Avaliação e Progresso do Ensino Superior e dispõe sobre a avaliação do ensino superior. Diário Oficial [da República Federativa do Brasil], Brasilia, DF, 16 dez. 2003c. Disponivel em: <https://www.planalto.gov.br/ccivil_03/MPV/ Antigas_2003/147.htm>. Acesso em: 25 nov. 2009. 
BRASIL. Ministério da Educação. Portaria $n^{\circ} 4$ de 5 de agosto de 2008. Regulamenta a aplicação do conceito preliminar de cursos superiores, para fins dos processos de renovação de reconhecimento respectivos, no âmbito do ciclo avaliativo do SINAES instaurado pela Portaria Normativa $n^{\circ} 1$, de 2007. Diário Oficial [da República Federativa do Brasil], Brasilia, DF, 06 ago. 2008a. Disponivel em: <http://www.inep.gov.br/download/superior/condicoesdeensino/ Portaria_N_4_de_5_de_agosto_2008.pdf>. Acesso em: 27 nov. 2009.

BRASIL. Portaria $\mathrm{n}^{\circ} 12$ de 5 de setembro de 2008. Institui o Índice Geral de Cursos da Instituição de Educação Superior (IGC). Diário Oficial [da República Federativa do Brasil], Brasilia, DF, set. 2008b. Disponivel em: <http:// www.inep.gov.br/download/superior/condicoesdeensino/ PORTARIA_NORMATIVA_12.pdf $>$. Acesso em: 27 nov. 2009.

Portaria n 300 de 30 de janeiro de 2006. Aprova o Instrumento de Avaliação Externa de Instituições de Educação Superior do Sistema Nacional de Avaliação da Educação Superior - SINAES. Diário Oficial [da República Federativa do Brasil], Brasilia, DF, 31 jan. 2006b. Disponivel em: <http://www.inep.gov.br/ download/superior/2006/avaliacao_institicional/Portaria_n300_30_01_06.pdf>. Acesso em: 27 nov. 2009.

Portaria $n^{\circ} 563$ de 21 de fevereiro de 2006. Aprova, em extrato, o Instrumento de Avaliação de Cursos de Graduação do Sistema Nacional de Avaliação da Educação Superior - SINAES. Diário Oficial [da República Federativa do Brasil], Brasília, DF, 22 fev. 2006c. Disponivel em: < http://www.inep.gov.br/ download/superior/2006/avaliacao_institicional/ portaria_MEC_563_21_2_2006.pdf>. Acesso em: 27 nov. 2009.

. Portaria no 879 de 30 de julho de 1997. Diário Oficial [da República Federativa do Brasil], Brasilia, DF, 31 jul. 1997b. Disponivel em: <http:// www.abmes.org.br/_Download/Associados/Legislacao/1997/Portaria/ po087997.htm>. Acesso em: 27 nov. 2009.

. Portaria no 972 de 22 de agosto de 1997. Diário Oficial [da República Federativa do Brasil], Brasília, DF, 26 ago. 1997c. Disponivel em: <http:// portal.mec.gov.br/sesu/arquivos/pdf/Portaria972.pdf>. Acesso em: 27 nov. 2009.

. Portaria $n^{\circ} 1.310$ de 17 de julho de 2006. Dispõe sobre a Composição da Comissão Técnica de Acompanhamento da Avaliação - CTAA, de que trata o artigo $1^{\circ}$ da Portaria n 1.027, de 15 de maio de 2006d. Diário Oficial [da República Federativa do Brasil], Brasília, DF, 18 jul. 2006. Disponivel em: < http://www.inep.gov.br/superior/ avaliacao_institucional/legislacao.htm>. Acesso em: 27 nov. 2009. 
Portaria $n^{0} 1.751$ de 27 de outubro de 2006. Dispõe sobre a relação nominal dos avaliadores de instituições de educação superior e de cursos de graduação, selecionados pela Comissão Técnica de Acompanhamento da Avaliação - CTAA, que passam a integrar o Banco de Avaliadores do Sistema Nacional de Avaliação da Educação Superior - BASis. Diário Oficial [da República Federativa do Brasil], Brasilia, DF, 30 out. 2006e. Disponivel em: < http://www.inep.gov.br/ superior/avaliacao_institucional/legislacao.htm>. Acesso em: 27 nov. 2009.

.. Ministério da Educação. Portaria n 2.051 de 9 de jul. de 2004. Regulamenta a Lei do SINAES. Diário Oficial [da República Federativa do Brasil], Brasilia, DF, 12 jul. 2004c. Disponivel em: < http://www.inep.gov.br/superior/ avaliacao_institucional/legislacao.htm>. Acesso em: 27 nov. 2009.

BRASIL. Portaria n 4.362 de 29 de dez. de 2004. Institui o Banco Único de Avaliadores da Educação Superior do Ministério da Educação, tendo como referência o perfil do docente avaliador. Diário Oficial [da República Federativa do Brasil], Brasília, DF, 30 dez. 2004d. Disponivel em: < http://www.inep.gov.br/ superior/avaliacao_institucional/legislacao.htm>. Acesso em: 27 nov. 2009.

BRESSER PEREIRA, L. C. Da administração pública burocrática à gerencial. In: BRESSER PEREIRA, L. C.; SPINK, P. (Org.). Reforma do Estado e administração pública gerencial. Rio de Janeiro: Fundação Getúlio Vargas, 1998.

CONSELHO NACIONAL DE EDUCAÇÃO (Brasil). Câmara de Educação Superior. Parecer n 1.070, de 23 de novembro de 1999. Critérios para autorização e reconhecimento de cursos de Instituições de Ensino Superior. Diário Oficial [da República Federativa do Brasil], Brasilia, DF, 27 jan. 2000. Disponivel em: <http://portal.mec.gov.br/cne/arquivos/ pdf/1999/pces1070_99.pdf>. Acesso em: 25 nov. 2009.

CONSELHO NACIONAL DE EDUCAÇÃO (Brasil). Câmara de Educação Superior. Parecer no 1.366, de 12 de dezembro de 2001. Dispõe sobre o credenciamento, transferência de mantença, estatutos e regimentos de instituições de ensino superior, autorização de cursos de graduação, reconhecimento e renovação de reconhecimento de cursos superiores, normas e critérios para supervisão do ensino superior. Diário Oficial [da República Federativa do Brasil], Brasilia, DF, 12 dez. 2001. Disponivel em: <http:// portal.mec.gov.br/cne/arquivos/pdf/2001/pces1366_01.pdf>. Acesso em: 25 nov. 2009.

CONSELHO NACIONAL DE EDUCAÇÃO (Brasil). Câmara de Educação Superior. Parecer $n^{\circ}$ 267, de 4 de setembro de 2002. Reexame do Parecer CNE/CES 111/ 2002, que dispõe sobre recredenciamento de Universidades e de Centros Universitários Diário Oficial [da República Federativa do Brasil], Brasilia, DF, 4 set. 2002. Disponivel em: <http://portal.mec.gov.br/cne/arquivos/pdf/2002/ pces267_02.pdf>. Acesso em: 27 nov. 2009. 
CONSELHO NACIONAL DE EDUCAÇÃO (Brasil). Câmara de Educação Superior. Resolução $n^{\circ} 1$, de 4 de maio de 2005. Dispõe sobre a composição das Comissões Multidisciplinares de Avaliação de Cursos e sua sistemática de atuação. Diário Oficial [da República Federativa do Brasil], Brasília, DF, 5 maio 2005. Disponível em: <http://www.cpa.unifei.edu.br/arquivos_upload/legislacao/2005resolucao_INEP01_05.05.05.pdf>. Acesso em: 27 nov. 2009.

DIAS, C. L.; HORIGUELA, M. L. M.; MARCHELLI, P. S. Políticas para avaliação da qualidade do Ensino Superior no Brasil: um balanço crítico. Educação e Pesquisa, São Paulo, v. 32, n. 3, p. 435-464, set./dez., 2006.

DIAS SOBRINHO, J. Avaliação da educação superior. Rio de Janeiro: Vozes, 2000.

DI PIETRO, M. S. Z.. Meios de controle em direito sanitário. Salvador, 2005. Disponivel em: <http://www.saude.ba.gov.br/conferenciaST2005/cdrom>. Acesso em: 15 set. 2006 .

FERNANDEZ LAMARRA, N. Educación superior y calidad en América Latina y Argentina: los procesos de evaluación y acreditación. Buenos Aires: IESALC: EDUNTREF, 2007.

GINKEN, H. J.A; DIAS, M.A. Retos institucionales y políticos de la acreditación en el ámbito internacional. In: GLOBAL UNIVERSITY NETWORK FOR INOVATION (GUNI). La educación superior en el mundo 2007: acreditación para la garantía de la calidad: qué está en juego?. Madri, Mundi Prensa Ed., 2006.

GOMES, A. M. Política de avaliação da educação superior: controle e massificação. Educação \&t Sociedade, Campinas, v. 23, n. 80, p. 275-298. set. 2002.

INEP. Orientações gerais para o roteiro da das instituições autoavaliação. [Brasilia, DF] 2004. Disponivel em:<http://www.inep.gov.br/download/superior/ sinaes/ orientacoes_sinaes.pdf>. Acesso em: 12 nov. 2009.

INEP. Portaria n ${ }^{\circ}$ 106, de 23 de julho de 2004. Nomeia os membros da Comissão de Avaliação Institucional. Diário Oficial [da República Federativa do Brasil], Brasilia, DF, 23 jul. 2004. Disponivel em: <http://www.inep.gov.br/superior/ avaliacao_institucional/legislacao.htm>. Acesso em: 27 nov. 2009.

INEP. Relatório do Curso de Pedagogia: ENADE 2005. Pelotas, RS: Universidade Católica de Pelotas, 2005. 
INEP. Relatório-síntese do ENADE de 2004 do Curso de Agronomia. Brasilia, DF, 2004. Disponivel em: <http://www.inep.gov.br/download/superior/enade / Relatorio/Relatorio_area_Agronomia.pdf>. Acesso em: 27 de nov. de 2009.

INEP. Roteiro de autoavaliação institucional. Brasília, 2005. Disponível em: <http:/ /portal.mec.gov.br/arquivos/pdf/roteiro.pdf>. Acesso em: nov. 2005.

KROTSCH, P. Educación superior y reformas comparadas. Buenos Aires: Universidad Nacional de Quilmes Editorial, 2003

MENEGHEL, S. M.; BERTOLIN, J. C. G. Reflexão sobre objetivos e procedimentos adotados pelas Comissões de Avaliação das Condições de Ensino (ACE) do INEP. Educação Temática Digital, Campinas, v. 5, n. 11, p. 115-145, 2003. Disponível em: <http://www.bibli.fae.unicamp.br/etd/doss01v5n1.pdf >. Acesso em: 24 de nov. de 2009.

NEVES, L. M. W. Legislação e planejamento no processo de privatização da educação superior. In: NEVES, L. M. W. (Org.) O empresariamento da educação: novos contornos do ensino superior no Brasil dos anos 1990. São Paulo: Xamã, 2002.

NUNES, E. O governo Lula e as mudanças nas agências reguladoras. Rio de Janeiro: Observatório Universitário, 2005. (Documento de trabalho; n. 17).

ROTHEN, J. C. Avaliação e política institucional: estudo dos indicadores qualificação docente na avaliação das condições de oferta de cursos. Avaliação, Campinas, v. 7, n. 3, p. 153-186, 2002.

SOUZA, P. N. P. LDB e educação superior. estrutura e funcionamento. 2. ed. São Paulo: Pioneira, 2001.

Recebido em: 24/08/2008

Aceito para publicação em: 09/04/2009 